\title{
A GRAMÁTICA GERATIVA NA ESCOLA: O PENSAR LINGUISTICAMENTE
}

\author{
THE GENERATIVE GRAMMAR IN THE SCHOOL: \\ THINKING LINGUISTICALLY
}

\author{
Ronald Taveira da Cruz | Lattes | ronaldtaveira@gmail.com \\ Universidade Federal do Piauí
}

\begin{abstract}
Resumo: Desde que o programa gerativo ganhou força nos estudos linguísticos, uma das perguntas mais frequentes é se ele pode ter algum impacto na escola, isto é, o que dele é possível aproveitar para o ensino da gramática. $\mathrm{O}$ ensino da gramática é uma questão que tem sido discutida amplamente por professores de Língua Portuguesa e linguistas, com propostas que vão desde uma revisão da gramática até o seu total abandono. Porém, acreditamos que o ensino da gramática deve ser mantido, mas não da forma que está. Podemos rever algumas concepções de ensino da gramática, dentre elas, a gramática como disciplina normativa, o ensino da gramática como transmissão de conteúdos de livros didáticos ou das próprias gramáticas, etc. O objetivo deste trabalho, então, é rever essas concepções e desenvolver uma forma de utilizar algumas noções teóricas (e práticas) com as quais o programa de Chomsky tem avançado. Portanto, este trabalho procura mostrar como algumas noções gerativas podem ser utilizadas na escola, com dois objetivos centrais: $o$ primeiro é o de incentivar o formalismo e a pesquisa na escola, isto é, florescer o pensar científico dos alunos, e o segundo, a produção linguística.
\end{abstract}

Palavras-chave: Gramática; Gerativismo; Escola.

Abstract: Since the generative program has gained strength in language studies, one of the most frequently asked questions is whether it can have any impact on the school, that is, how the program can be used to teach grammar. The teaching of grammar is an issue that has been widely discussed by Portuguese language teachers and linguists, with proposals ranging from a review of the grammar to its total abandonment. However, we believe that the teaching of grammar should be maintained, but not as it is. We can revise some conceptions of grammar teaching, among them, grammar as prescriptive discipline, grammar teaching as transmission of textbook content or of the grammars themselves etc. The purpose of this work is then to review these concepts and develop some theoretical notions (and practices) with which the Chomsky program has advanced. Therefore, this work seeks to show how some generative notions can be used in school, with two central objectives: the first is to encourage formalism and research in school, that is, to flourish the students' scientific thinking, and the second, linguistic production.

Keywords: Grammar; Generativism; School. 


\title{
1 Introdução
}

O estudo da gramática na escola provoca desafios para o professor, porque ele precisa ao mesmo tempo aprimorar o aluno para ser um falante e escritor com competência para lidar com vários cenários linguísticos do dia a dia e também prepará-lo para enfrentar o vestibular, o Exame Nacional do Ensino Médio (ENEM), os concursos etc. O título deste artigo se baseia em uma expectativa provocadora ao programa gerativo de Chomsky: Como podemos aplicar a teoria gerativa no ensino? Quais as consequências do programa chomskiano para o ensino da gramática? A descrença em sua relevância e aplicabilidade no ensino é quase total, porém, este artigo defende a ideia de que é possível pensar linguisticamente (HONDA; O’NEIL, 2008), dentro de sala de aula, com base no programa gerativo.

Em uma de suas visitas ao Brasil, em 1996, Chomsky (1996, p. 73-74) é questionado:

\begin{abstract}
Nós, professores, estamos muito angustiados de perceber que, apesar dos avanços na gramática gerativa, o ensino de gramática nas escolas de primeiro e segundo graus continua sendo nos moldes da gramática tradicional. O professor acha que é necessário "ensinar" gramática nas escolas? Caso afirmativo, como abordá-la de forma que se aproxime do modelo gerativo?
\end{abstract}

Na própria pergunta que se coloca, percebe-se uma confusão de ideias. A indagação em si tenta reunir dois conceitos bastante diferentes: a evolução da gramática gerativa e a evolução do ensino de gramática na escola. O primeiro tem a ver com pesquisas desenvolvidas, é de base teórica e fundamentalmente epistêmico. O segundo simplesmente retrata uma determinada sociedade e seus valores, seus objetivos no ensino. Trata-se de uma questão complexa quando comparada a uma teoria, pois é parte da prática docente educacional. Chomsky (1996, p. 74) também assim o vê: "Como se deve ensinar depende de todo tipo de questão. Essas questões não têm nada a ver como a língua funciona. Têm a ver com os objetivos do sistema educacional, com problemas sociais e políticos.”

Neste trecho, fica claro que o ensino de línguas, especificamente o ensino da gramática envolve vários fatores, como as relações entre política e Linguística e entre poder e linguagem, o social na linguagem e a ideologia, que estão além dos objetivos deste texto.

A questão que se coloca para a teoria gerativa sobre sua aplicabilidade no ensino nada tem a ver com o gerativismo em si. É uma questão de cunho pedagógico, e deve ser respondida juntamente com a linguística. Está relacionada também à pedagogia e às polí- 
ticas públicas, sociais e educacionais. Se a proposta é ensinar a gramática tradicional para a exclusão de pessoas, então, o ensino da língua portuguesa a partir da gramática tradicional vem funcionando bem. Nesse sentido, é verdade que "[...] o tipo de transgressão pelo qual certas sentenças aparecem como mal formadas aos falantes não é, de fato, sintático mas ideológico...” (ILARI, 2003, p. 54). Por outro lado, se o intuito é formar críticos e pesquisadores que entendam o que é a linguagem humana e, desse modo, usem-na com propriedade nos diversos contextos, então, a Linguística tem muito a contribuir e, no caso do ensino da gramática, o programa gerativo tem instrumentos conceituais que podem auxiliar. Pesquisas nas universidades brasileiras dentro da própria área da Linguística têm se preocupado com tais questões. Vertentes da Linguística relacionadas ao ensino e à pratica pedagógica têm como eixo condutor a questão do preconceito linguístico, do letramento e da oralidade, da educação em língua materna e da aquisição da língua oral e escrita. Não se pode pensar em educação em língua materna sem que a Linguística e a educação/ pedagogia trabalhem juntas.

Chomsky (1996) segue sua resposta afirmando que as pessoas têm de estar motivadas para aprender, porque, caso contrário, não há modelo de ensino que resolva os problemas. A motivação no ensino de gramática é um processo de conscientização que parte do que é desinteressante para o que é interessante, do que é desprezível para o que é relevante, visando tornar o aluno competente em um aluno habilidoso. $\mathrm{O}$ aluno competente conhece sua língua, monitora sua estrutura, articula os elementos linguísticos de forma natural e processa infinitos campos significativos. Já o aluno habilidoso consegue usar esse conhecimento linguístico em várias situações de fala ou escrita. Então, a proposta é formar um aluno competente-habilidoso.

Desse modo, o que motiva este texto é o que esperamos motivar no aluno: a capacidade de fazer-ciência, e mais, a habilidade de fazer-ciência e, no caso do ensino da linguagem, pensar linguisticamente (HONDA; O’NEIL, 1993; 2008), até porque a linguagem é constitutiva do ser (FRANCHI, 2002). Portanto, é tornar o aluno competente em um aluno habilidoso. Este trabalho, então, tem duas finalidades congruentes: A primeira é mais geral e é uma questão da Linguística como um todo, pois trabalha com a hipótese de que a Linguística tem de estar na escola ou pelo menos, refletir-se na escola; a segunda abrange aqueles que ainda acreditam que a gramática na escola é fundamental e que a teoria gerativa pode ser um auxílio importante para o professor(a) de gramática. Essas duas finalidades podem ser parafraseadas em duas perguntas: 
1) Por que Linguística na escola?

2) Por que o programa gerativo na escola?

Com o propósito de trabalhar essas duas perguntas, desenvolvemos na primeira parte uma breve abordagem da Linguística na escola, de sua importância para promover a capacidade de fazer-ciência no aluno. Em seguida, motivamos a introdução mais direta do programa de Chomsky na escola. Por fim, um modelo de aula é exemplificado.

\section{Por que Linguística na escola?}

O ensino da gramática tradicional está estritamente ligado ao ensino de uma terminologia complicada e problemática, limitando a prática aos exercícios escritos, ignorando as variedades linguísticas, fortificando os preconceitos e abusos de poder. $\mathrm{O}$ que a Linguística faz é semear uma nova forma de atuação: "a primazia da expressão falada sobre a expressão escrita" (ILARI, 1997, p. 99). Assim, o professor, ao conhecer como a língua funciona, não pode esquecer que a oralidade também é constitutiva da língua e é ela a língua materna em constante mudança. $\mathrm{O}$ que falamos, o que está em uso é a própria língua em questão. Ensinar apenas o que está escrito é ensinar uma língua morta e “[...] a língua nunca pode ser estudada ou ensinada como um produto acabado, fechado em si mesmo" (GERALDI, 1996, p. 28).

O entendimento da Linguística como um todo, como uma disciplina capaz de agregar a oralidade e a escrita na formação do aluno, deve ser pensado como essencial na formação do professor que irá atuar com esse aluno. De acordo com ILARI (1997), existe uma necessidade de unir aquele que ensina e aquele que pesquisa a língua. É o que também afirma Chomsky (1996, p. 74): “[É] útil para os professores entender como a língua funciona, exatamente como um professor de natação deve saber algo sobre fisiologia. Mas se se deve usar essa informação no ensino é outra questão". Uma questão que deve ser respondida afirmativamente.

Nota-se que o "perfil ideal” do professor de gramática pode ser facilmente traçado. Encontrá-lo, porém, não é algo simples, ou melhor, formar um profissional ideal não é tão simples assim. A Linguística vê no profissional de ensino um grande conhecedor da língua e de suas variedades, que incentiva a pesquisa e a pluralização do idioma, sem jamais estigmatizar nenhuma dessas variedades, e sim explicando ao aluno os contextos de interação social em que a língua pode variar. Dessa maneira, estaremos transformando o aluno em um ser consciente de sua própria língua, contribuindo para sua formação enquanto ser linguístico. 
O reflexo dos estudos linguísticos na escola é claro. Há tempos, suas influências são vistas desde as mudanças dos Parâmetros Curriculares Nacionais (PCNs) até o dia a dia do professor. As preocupações com as noções de preconceito linguístico, variedades da língua, dialetos, norma culta/oculta, entre outras, advêm da Linguística e devem ser (re) tomadas didaticamente por professores. Com isso, espera-se que eles possam atuar de maneira mais crítica e questionadora, revisando as definições da gramática, salientando as interações discursivas e as intenções de cada uma das variedades e variações de uso da língua materna. Espera-se também que a produção de textos seja feita de maneira mais pertinente, cuidando para que não se perca o uso da oralidade; enfim, que trabalhem com as contribuições da Linguística no ensino de Língua Portuguesa.

A situação se torna mais tensa se pensarmos em qual língua ensinar. Não é a intenção deste artigo discutir tal questão, mas é possível um devaneio: A criança, ao nascer, já percebe os sons a sua volta. Ela distingue sons linguísticos de sons não linguísticos, ela consegue identificar o ritmo, não só de sua língua materna, mas de todas as línguas existentes no mundo, e pouco a pouco vai amadurecendo sua própria língua. Chomsky (2000) faz a distinção entre língua-I e língua-E. Língua-I é uma instanciação do órgão da linguagem, parte de nosso dote genético. O 'I' dessa língua-I significa individual, interna e intensional: É individual, porque cada um tem a sua a partir de princípios mentais, independentemente do ambiente; é interna, porque está na mente-cérebro, é uma instanciação do órgão da linguagem, parte de nosso dote genético; e é intencional, pois é uma função que converte palavras em descrições estruturais, por exemplo, uma função que pega as palavras Joana e surfa e converte em Joana surfa. A língua-E, pelo contrário, é externa à mente-cérebro e não individual. A língua-E é uma linguagem pública, é um objeto social estabelecido por convenção e dependente do ambiente ou da comunidade. Ela privilegia a dimensão social, histórica e cultural da linguagem.

A partir dessa distinção chomskiana, temos ao menos duas línguas: uma, que é um patrimônio (DUARTE, 2016) a se desenvolver durante os primeiros anos, naturalmente, sem professor, sem auxílio e de forma rápida e "fácil", tendo em vista a complexidade do sistema linguístico; e outra, que é aprendida na escola, que, de acordo com a visão tradicional do ensino do português, é bem diferente. Drummond já nos mostrou isso em seu poema 'Aula de português', assim como Mattos e Silva (2004), em seu livro “O português são dois..... Nesse contexto, porém, Mattos e Silva (2004) propõe que existe outra gramática que deve ser ensinada na escola, aquela que os falantes sabem, ou, em outras palavras, aquela em que os falantes usam no dia a dia: sua fala. Em relação a isso, temos o 
belo projeto Gramática do Português Culto Falado no Brasil, que nos fornece uma fonte legítima do que "realmente" deve ser ensinado na escola.

Para avançar mais e baseando-se na ideia de língua-I, Kato (2005) - bastante iluminada, como sempre - afirma que nosso belo idioma são três. Como dito anteriormente, não é a intenção deste artigo entrar nessa discussão, mas a autora defende que devemos ensinar essa gramática baseada na língua-I, que sofre a variação linguística tão discutida pela linguística brasileira (CASTILHO, 2010; BAGNO, 2011; TARALLO, 1987; TARALLO; KATO, 1989; HORA; CHRISTIANO, 1999; MARTINS; COELHO; CAVALCANTE, 2015; DUARTE, 2012, entre outros). Este artigo corrobora essa ideia de Kato (2005) e, no próximo tópico, o programa gerativo e a escola ganham mais harmonia.

\section{Por que o programa de Chomsky na escola?}

Primeiro, porque há consensualmente por parte dos linguistas

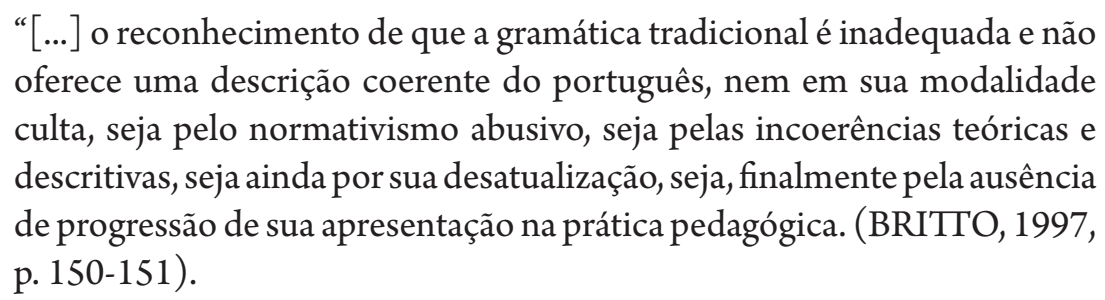

Segundo, porque

[a]prender uma língua não é apenas conhecer o conjunto de normas linguísticas referentes a ela, mas é também tornar-se sensível às percepções culturais diferentes... e ser capaz de desvendá-la a partir das marcas linguísticas formais. (CASTRO, 1990, p. 66).

De acordo com Chomsky (1986), a gramática gerativa nada mais é do que uma gramática explícita que se preocupa com a forma e o significado das expressões dessa língua e, ainda mais, com a mente do indivíduo, que tem uma gramática implícita em sua cabeça. Ela pressupõe uma base psicológica (e, por que não dizer? também biológica) do indivíduo e uma concepção modular da mente: Postula-se a existência de um módulo responsável pela linguagem e, dentro desse módulo, a faculdade da linguagem (FL) - aparato genético do ser humano relacionado especificamente com a linguagem. Naturalmente, para a FL se desenvolver ou amadurecer, ela precisa da interação da criança com a comunidade de fala. 
A base para os estudos científicos da linguagem é um conceito associado de gramática - por esse termo entende-se a gramática interna do falante ou conhecimento implícito:

[...] qualquer falante de português possui um conhecimento implícito altamente elaborado da língua, muito embora não seja capaz de explicitar esse conhecimento. E veremos que esse conhecimento não é fruto de instrução recebida na escola, mas foi adquirido de maneira tão natural e espontânea quanto a nossa habilidade de andar. Mesmo pessoas que nunca estudaram gramática chegam a um conhecimento implícito perfeitamente adequado da língua. São como pessoas que não conhecem a anatomia e a fisiologia das pernas, mas que andam, dançam, nadam e pedalam sem problemas. (PERINI, 1996, p. 13).

Com o surgimento da gramática internalizada, não há mais noção de erro. O verdadeiro objeto da Linguística passa a ser um componente do mundo natural (COSTA, 1994, p. 83). O objetivo da educação linguística escolar passa a ser o desenvolvimento das habilidades de ler, escrever, falar e escutar, que tem como base a concepção heterogênea da língua inserida em um processo ininterrupto e contínuo que se inicia na infância e se institucionaliza na escola, quando o aluno entra em contato com as várias situações de uso da língua.

Sem essa noção de erro, o que entra em jogo é a dicotomia gramatical/agramatical. Esse é mais um argumento para que o programa de Chomsky seja trabalhado na escola: Todos os alunos falam sua língua (a oralidade, novamente), e eles são capazes de distinguir intuitivamente sentenças gramaticais, como (a) quem comprou o jornal ontem?, de sentenças agramaticais, como * jornal o comprou ontem quem?. É o que se chama de ciência intuitiva.

Outro argumento importante para a introdução do programa de Chomsky na escola parte da forma de investigação do modelo. A investigação é feita pela dedução, que parte de grandes generalizações, princípios, do raciocínio dedutivo, para ir depois aos dados, para corroborar ou não a teoria. A consequência mais valiosa para o ensino, e para o aluno propriamente, é que os alunos começam a se interessar pela construção e pela destruição de teorias, fomentando o pensamento científico. Mais uma vez, há o incentivo no desenvolvimento da capacidade de fazer-ciência no aluno.

Um dos fatores que distancia o programa gerativo do ensino de português, e especificamente, do ensino da gramática, é a ideia ultrapassada de que tal programa trabalha apenas com falantes ideais. Duarte (2016, p. 29) consegue colocar um ponto final nessa 
antiga discussão sobre o "problema" do gerativismo e afirma que já passou da hora de avançar:

\begin{abstract}
Aliás, isso nos leva a outra afirmação equivocada, que vamos, aos poucos, eliminando: "a teoria gerativa não está interessada em dados reais; só trabalha coma gramática do falanteideal”. Comoé, então, que os gerativistas estudam a aquisição da linguagem? Como é que os gerativistas estudam a mudança linguística? É claro que há, entre os gerativistas, aqueles que se interessam por análises formais e não precisam de um conjunto exaustivo de dados para desenvolvê-las. Mas quem busca acompanhar a aquisição e a mudança não pode prescindir de dados reais e robustos!!!!. Basta ver o importante trabalho sobre aquisição desenvolvido por Ruth Lopes (2003, entre outros), dentro da perspectiva formalista, e por Christina Abreu Gomes (2013), sobre aquisição de variação estruturada, à luz de modelos multirrepresentacionais, entre tantos outros, e o trabalho realizado por discípulos de Tarallo e Kato e por Charlotte Galves, que vêm desvendando, juntamente com seus orientandos e colaboradores, "as gramáticas do português", com base numa grande amostra, com anotação sintática, que abarca dos séculos XVI a XIX o corpus Tycho Brahe, disponível na internet. Entre os mais jovens gerativistas que sabem o valor dos dados reais e não abrem mão deles para seus trabalhos, podemos citar Sílvia Cavalcante, da UFRJ, Juanito Avelar, da Unicamp, Marco Antônio Martins, da UFSC, entre tantos outros, cujo trabalho tem permitido generalizações empíricas e formais importantíssimas.
\end{abstract}

Outros trabalhos elegantes também fomentam essa ideia de que precisamos avançar e usar o programa gerativo na escola. Vicente e Pilati (2012) argumentam que certos conceitos, como competência, devem ser revistos nos Parâmetros Curriculares Nacionais. Os PCNs trazem uma inovação importante: a diferença entre competência e habilidade. Jogue uma pedra quem não aceitar que tal diferença é fruto do avanço do programa gerativo, estritamente, a diferença chomskiana entre competência e desempenho (performance). Os PCNs precisam assumir que a competência engloba a gramática universal - ao menos o conjunto de conhecimentos inatos - e os conhecimentos linguísticos amadurecidos no curso da experiência.

Kenedy (2013) é bem claro nesse aspecto, ao discutir não só o empreendimento gerativo, mas também a noção de sintaxe gerativa. O termo gerativo vem da ideia de que o sistema linguístico é capaz de gerar um número infinito de sentenças a partir de um número finito de elementos linguísticos: É a sintaxe a responsável por essa combinação infinita de tais elementos, a partir de regras ou princípios sintáticos. Então, a sintaxe gerativa procura compreender como as regras do componente sintático se comportam nas diversas línguas naturais. Nesse sentido, o sintaticista gerativo quer descrever quais regras 
de uma língua geram estruturas sintáticas gramaticais e, paralelamente, não possibilitam estruturas agramaticais. Por isso, na escola, é interessante o professor trabalhar a diferença entre sentenças gramaticais e agramaticais presentes na língua portuguesa.

Pires de Oliveira e Quarezemin (2016) vão mais longe, ao propor que os alunos reflitam sobre sua língua e construam gramáticas em sala de aula, em vez de decorarem conceitos da gramática tradicional ou de qualquer outra gramática já pronta. $\mathrm{O}$ aluno de Língua Portuguesa se torna, assim, o próprio gramático, e as aulas de Português um laboratório onde hipóteses científicas e gramáticas são construídas:

Nossa proposta é que as aulas de português incluam momentos de práticas reflexivas sobre as línguas em geral e sobre a língua dos alunos... A ideia é pôr a mão na massa, construir pequenas gramáticas, gramáticas de um fragmento de uma língua... A proposta é que o aluno seja o gramático, que ele construa as gramáticas... $\mathrm{O}$ aluno aprende a construir hipóteses científicas enquanto constrói uma gramática. (PIRES DE OLIVEIRA E QUAREZEMIN, 2016, p. 15-16).

O pensamento científico está enraizado em um comprometimento com a ciência: a clareza, previsão, explicação. Para que tenha sucesso, a teoria científica, então, é desenvolvida em um modelo, como se entende na matemática. Sendo assim, o programa de Chomsky na escola tem um caráter interdisciplinar, se relacionando com a matemática. Desse ponto de vista, estamos pensando em uma gramática formal, com preceitos e conceitos formais. É a partir dessa interdisciplinaridade que surgem alguns exemplos de aula de gramática.

\section{Aulas de gramática}

Ao se falar de gramática gerativa, fala-se de um ponto de vista mais amplo, de gramática formal na Linguística, que inclui não só uma sintaxe formal, mas uma fonologia, morfologia, semântica e pragmática formais (PIRES DE OLIVEIRA, 2004). Há inúmeras formas de trabalhar a intuição dos alunos, como falantes de língua, sob uma perspectiva formal. Por exemplo, é possível revelar a competência dos alunos a partir da intuição, algo que o professor de gramática deve explorar:

(1) A manga está suja.

O que está em jogo no exemplo (1) é a percepção da ambiguidade lexical de manga: pode ser a fruta ou a parte da roupa. A ambiguidade também pode ser estrutural: 
(2) O padre percebeu a fumaça da torre da igreja.

Na sentença em (2), é possível tecer algumas interpretações que se baseiam na estrutura e na relação entre as palavras. Se alguém pergunta o padre percebeu o quê?, a resposta é uma interpretação possível: a fumaça da torre da igreja, ou seja, não entra em cena o local onde o padre se encontrava. Se a pergunta for o padre percebeu a fumaça de onde?, a resposta é: da torre da igreja, isto é, a fumaça acontecia na torre da igreja e o Padre estava em outro local; outra interpretação é que o padre estava na torre da igreja, mas a fumaça era em um local diferente. Ainda, outra possibilidade é que o padre estava na igreja e percebeu a fumaça que acontecia na torre. Ou seja, é papel do professor provocar tais interpretações e pesquisar junto com os alunos como a gramática possibilita isso.

Essa ambiguidade estrutural pode ser explorada em sala de aula a partir da noção de constituinte, um conceito sintático primordial do programa gerativo. Observe-se a próxima sentença:

(3) O professor viu a teoria gerativa na sala de aula.

Na sentença (3), o núcleo das relações sintáticas é o verbo ver. Ele controla três constituintes: o professor, a teoria gerativa e na sala de aula. Essa sentença é ambígua: Em uma interpretação, temos Foi na sala de aula que o professor viu a teoria gerativa; em outra, temos Foi a teoria gerativa na sala de aula que o professor viu. Na primeira interpretação, na sala de aula é o lugar onde a teoria gerativa foi vista pelo professor; na segunda, a teoria gerativa na sala de aula foi vista pelo professor, sem mencionar onde ela foi vista. Na primeira interpretação, o constituinte na sala de aula não faz parte do constituinte a teoria gerativa; já na segunda interpretação, faz parte. Como podemos observar, o constituinte é uma unidade sintática. Para entender melhor essa noção de constituinte, ver Mioto, Figueiredo Silva e Lopes (1991) e Kenedy (2013).

Da mesma forma que há ambiguidade na língua, há sinonímia lexical e estrutural. Nas sentenças (4) e (5), a seguir, isso é visível:

(4) Pedro comprou um carro.

(5) Pedro adquiriu um carro.

Mas nem sempre a sinonímia se mantém, caso se faça um exercício de combinação de palavras. Por exemplo, a palavra completo é sinônima de concluído, acabado, inteiro... Se se acrescentam tais "sinônimos" na sentença (4), é possível perceber que os significados mudam, trazendo até interpretações contraditórias: 
(6) Pedro comprou um carro completo.

(7) Pedro comprou um carro concluído.

(8) Pedro comprou um carro acabado.

(9) Pedro comprou um carro inteiro.

Você, leitor, consegue perceber a diferença? Na sentença (6), a ideia é que o carro possui todos os opcionais possíveis, como vidro elétrico, ar condicionado etc. No exemplo (7), Pedro comprou um carro que estava pronto, finalizado. Já as sentenças (8) e (9) parecem antônimas: Um carro acabado remete a um carro descuidado, batido, que possivelmente vai frequentar bastante as oficinas; já um carro inteiro significa o oposto, que o carro é bom, conservado etc. Como se percebe, o significado da palavra depende também daquilo que está ao seu redor, sua estrutura na sentença, seu potencial combinatório.

Na língua, o falante reconhece quando é possível usar um termo ou não na sentença. Os exemplos a seguir ilustram isso:

(10) Eu não bebi nenhum drink.

(11) *Eu bebi nenhum drink.

(12) Nenhuma menina veio.

(13) *Nenhuma menina não veio.

O que está em jogo nessa sentença é a combinação de termos ou sintagmas negativos como nenhum (a) e não. Em alguns casos, tal combinação é impossível, como é evidente na sentença (13). A sentença (11) é agramatical porque não há nenhuma negação explícita. A sentença (10) é gramatical porque parece haver alguma regra que licencia o sintagma de negação não antes de nenhum (a), mas o contrário não é possível como se percebe na agramaticalidade (13). Fazer com que os alunos percebam essas combinações, em quais contextos ocorrem, quais as restrições, para que analisem sua distribuição e criem hipóteses, torna o trabalho do professor de gramática mais interessante. Dentro da gramática gerativa, isso é explicado pelo que se denomina de item de polaridade negativa (ILARI, 1984; MIOTO, 1992; NEGRI, 2006; SOUZA; GRITTI; PIRES DE OLIVEIRA, 2008).

Observe as sentenças a seguir:

(14) Os alunos gostam da gramática gerativa. 
(15) Gosto da gramática gerativa.

(16) Trovejou na Praia.

Do ponto de vista intuitivo, todas essas sentenças parecem indicar um sujeito, porque quem gosta, gosta de alguma coisa; e se trovejou, significa que algum ruído parecido com trovão aconteceu: como se tivesse algo como $O$ trovão trovejou. Então, o verbo gostar exige dois termos linguísticos, aquele que gosta e a coisa gostada, enquanto trovejar apenas um, muito semelhante ao exemplo a seguir, em que o verbo pede apenas um termo linguístico:

(17) O barco afundou.

À primeira vista, o verbo em (17) se comporta semelhantemente a verbos como surfar, dormir, cair... Mas, ele também pode parecer com o verbo gostar, que, como visto, exige dois termos linguísticos:

(18) Pedro afundou o barco.

(19) *Pedro caiu a pedra.

Como se percebe nesses exemplos, o verbo do tipo afundar parece se comportar como o verbo cair, mas se distancia desse em virtude da agramaticalidade de (19). Nesses exemplos, a noção de transitividade verbal da gramática tradicional entra em colapso, porque os dados indicam que não existe uma possibilidade única de classificação, algo como o verbo X é transitivo ou intransitivo. Para melhor compreender esses deslizes, ver Kanthack (2011), Perini (2008), Franchi (2003), Scher, Medeiros e Minussi (2009).

A gramática tradicional joga essas intuições para longe da sala de aula, porque trabalha com conceitos que confundem os alunos. Por exemplo, afirma que os termos da oração são compostos por essenciais (sujeito e predicado), integrantes (complementos do nome e verbo) e acessórios (adjuntos adverbias e nominais e o aposto). Como discutido, o verbo gostar exige dois termos linguísticos, logo, tanto o sujeito quanto o complemento verbal são essenciais. Você não pode apenas dizer Pedro gosta sem causar qualquer inquietação: Gosta de quê? De quem? Observe os exemplos a seguir:

(20) Pedro saiu.

(21) Pedro saiu ontem.

(22) Pedro saiu do show. 
(23) Pedro saiu do show agitado.

Os termos em destaque são acessórios segundo a gramática tradicional, o que significa que podem ser retirados da sentença, porque "não (são) rigorosamente necessários à compreensão básica do enunciado” (LUFT, 1986, p. 42). Mas se tais elementos estão ausentes, como em (20), os sentidos das sentenças são completamente diferentes: sair ontem e sair do show remetem a situações significativas bem diversas. Em (23), temos outra curiosidade, porque o termo agitado tanto pode estar modificando o termo show quanto o termo Pedro: No primeiro caso, o show que era agitado, enquanto no segundo, Pedro. Já a gramática gerativa não provoca essa confusão conceitual porque ela pressupõe que os verbos se combinam com argumentos e adjuntos em uma estrutura hierárquica. Em (21), por exemplo, Pedro é argumento do verbo sair, enquanto ontem, seu adjunto. Em (14) e (15), o verbo gostar tem dois argumentos, mas em (15), um deles está implícito, e assim por diante. Duarte (2007, p. 186) já nos mostra essa inconsistência da gramática tradicional, uma vez que tal perspectiva

[...] não contribui para uma visão das relações entre os constituintes da oração, além de induzir o aluno a pensar que os chamados termos 'essenciais' são mais importantes que os demais. À imprecisão resultante do uso de tais adjetivos alia-se a falta de complementaridade entre os termos que compõem cada um dos três grupos [...] essa forma de distribuir os termos da oração não contribui para o entendimento das relações gramaticais que se estabelecem entre eles.

Observe mais esses exemplos:

(24) Eu não gosto da GT, portanto não estudarei.

(25) Se mudar o ensino de gramática, eu estudarei.

Intuitivamente, ambas as orações são muito parecidas, porque tanto em (24) quanto em (25) aparecem duas sentenças com um verbo em cada. Do ponto de vista formal, o verbo é peça central na arquitetura sintática, porque ele escolhe se quer combinar com um, dois ou três argumentos. Além disso, as sentenças em cada um dos períodos acima acarretam alguma relação de dependência entre si, tanto sintática quanto semanticamente. Como provar isso? Pelo teste da inversão:

(26) *Portanto não estudarei, eu não gosto da GT.

(27) Eu estudarei, se mudar o ensino de gramática. 
Ao inverter a ordem da oração (24), temos uma combinação agramatical, como demonstra (26). Parece que existe alguma hierarquia na ordem das sentenças e que elas são dependentes sintaticamente entre si. Elas também o são semanticamente: Você não pode dizer Portanto não estudarei, do nada, sem que cause algum embaraço compreensivo. Já em (27), é possível perceber que existe uma certa independência na ordem das sentenças, porém o significado do todo é composto do significado das partes e as duas sentenças só fazem sentido juntas: Novamente, não faz sentido a sentença se mudar o ensino da gramática sozinha. Logo, as sentenças em (26) mantêm uma relação de dependência entre si, assim como em (27). Porém, não é bem isso que a gramática tradicional considera: Segundo essa perspectiva, as sentenças em (24) são independentes entre si e uma não rege a outra - são conhecidas como orações coordenadas; já em (25), as sentenças são dependentes - período composto por subordinação -, porque a segunda sentença necessita da primeira para existir, apesar de a primeira reger-se por si própria, sem exercer qualquer função sintática na outra sentença, dentro do mesmo período. Como se percebe, os preceitos da gramática tradicional são problemáticos e vão contra a intuição linguística.

A matemática, como um modelo para a teoria, é importante na representação semântica. Por exemplo, considere as seguintes sentenças:

(28) O homem é casado.

(29) Os homens são casados.

(30) Algum homem é casado.

(31) Três homens são casados.

Nessas quatro sentenças, o conhecimento pressuposto em matemática para montar um modelo é o da teoria dos conjuntos. Na sentença (28), a intersecção entre o conjunto dos homens e o conjunto dos casados tem de ser igual a um. Na sentença (29), essa mesma intersecção deve ser maior ou igual a dois. Em (30), a intersecção entre o conjunto dos homens e o dos casados tem de ser maior que um. Finalmente, na sentença (31), essa intersecção é igual a três. Honda e O’Neil (1993, p. 238) afirmam que as

relações complexas entre estrutura sintática e seu significado expressos em termos matemáticos básicos pode ser um foco da investigação linguística e pode também formar um modo de acessar o "tamanho" do conhecimento do aluno de um determinado aspecto. 
O professor também pode trabalhar o conhecimento linguístico e a intuição dos alunos em relação à gramaticalidade ou não de uma sentença ( $O$ aluno beijou a mão da professora vs. aluno o da mão beijou professora a), ou de sentenças nunca ouvidas antes (as bolas agradecem o cuidado azul), e até de palavras possíveis e impossíveis (desdormiu $\mathrm{x}$ iumrodesd), como nos aponta Westphal (1994). No mais, cabe ao professor de português explorar o fazer-ciência nos alunos, instigar que eles construam hipóteses científicas e sua própria gramática. E ao usar a gramática gerativa, o professor está se baseando em um programa de investigação científica (BORGES NETO, 2004), não em uma teoria em si, acabada e inalterável. Então, com esse raciocínio, professores e alunos são gramáticos pensam linguisticamente - e fazem parte desse programa.

\section{Considerações finais}

No campo atual da Linguística, não cabe mais falar de tradição no ensino de gramática, pois é fato concreto que o mesmo já não é, há alguns anos, eficaz. Na verdade, existem muitas críticas à maneira irracional e estanque do ensino, e várias propostas que visem a melhorá-lo, como foi mostrado parcialmente neste artigo. Este também foi um dos objetivos do presente artigo: propor o cunho científico em sala de aula.

$\mathrm{O}$ que se percebe é que a língua portuguesa merece e efetivamente precisa que se produzam gramáticas que estejam de acordo com os campos aqui explorados - pedagógicos e descritivos; mas que também seja visível nessa gramática o objeto sob análise e o tipo de manifestação que se mira: língua falada, escrita, que tipo de registro, enfim, da língua como manifestação particular de uma gramática universal, ou seja, "trata-se de levar os alunos desde cedo a diversificar os recursos expressivos com que fala e escreve e a operar sobre sua própria linguagem, praticando a diversidade dos fatos gramaticais de sua língua”. (FRANCHI, 1987, p. 41).

Pretende-se, também, enfocar a ideia de mover o aluno de competente para habilidoso. Habilidade é uma espécie de "inteligência capitalizada" que decorre da competência já adquirida. Navegar, por exemplo, é uma competência. Saber navegar em mar revolto é uma habilidade. Falar é uma competência. Saber falar bem em voz alta diante de um grande público é uma habilidade. O que se espera é que o aluno não apenas saiba "gramática", no sentido tradicional do texto, mas que ele seja habilidoso com sua língua, tornando-se um verdadeiro poliglota em sua própria língua, enfim, que o aluno seja o próprio gramático, ao pensar linguisticamente. 


\section{Referências}

BAGNO, M. Gramática pedagógica do português brasileiro. São Paulo: Parábola Editorial, 2011.

BORGES NETO, J. O empreendimento gerativo. In: MUSSALIN, F.; BENTES, A.

C. (Org.). Introdução à lingüística: fundamentos epistemológicos. São Paulo: Cortez, 2004, p. 93-130.

BRITTO, L. P. L. A sombra do caos: ensino de língua X tradição gramatical. Campinas: Mercado de Letras, 1997.

CASTILHO, A. de. Nova Gramática do Português Brasileiro. São Paulo: Contexto, 2010.

CASTRO, S. A. P. Que língua ensinamos? Letras: revista do instituto de Letras, v. 9, n. 1-2, dez. 1990.

CHOMSKY, N Knowledge of language: its nature, origin and use. New York: Praeger, 1986

. Linguagem e mente: pensamentos atuais sobre antigos problemas. Brasília: Editora Universidade de Brasília, 1996.

Press, 2000.

. New Horizons in the study oflanguage and mind. Cambridge: Cambridge University

COSTA, J. C. Linguagem-I X Linguagem-E na Lingüística C. Seminário Linguística e ensino da Língua Portuguesa. Anais do Seminário de Linguística e Ensino da Língua Portuguesa. Porto Alegre: Edipucrs, 1994.

DUARTE, M. E. L. Termos da oração. In: VIEIRA, S. R.; BRANDÃO, S. F. (Org.). Ensino de Gramática: descrição e uso. São Paulo: Contexto, p. 185-203, 2007.

. Sobre o ensino da gramática nos níveis Fundamental e Médio: por que, quando e como? Revista Matraga, v. 19, n. 30, p. 41-60, 2012.

. O papel da linguística na evolução dos estudos gramaticais no brasil. In: Sá Junior, L. e Martins, M. A. (Orgs.). Rumos da linguística brasileira no século XXI historiografia, gramática e ensino. São Paulo: Editora Edgard Blücher Ltda, p. 19-42 2016.

FRANCHI, C. Criatividade e gramática. Trabalhos em Lingüística Aplicada, n. 9, p. 5-45, 1987.

. Linguagem - atividade constitutiva. Revista do Gel, $50^{\circ}$ Seminário em memória de Carlos Franchi (1932-2001), número especial, p. 37-54, 2002.

. Predicação. Revista de Estudos da Linguagem, v. 11, n. 2, p. 17-81, 2003.

GERALDI, J. W. Linguagem e ensino - exercícios de militância e divulgação. Campinas: Mercado de Letras, 1996a.

HONDA, M.; O’NEIL, W. Triggering Science-forming capacity through linguistic inquiry. In: HEILER, K.; KAISER, S. J. (Ed.). The view from the Building 2: Essays in honor of Sylvain Bronberguer. Cambridge: The MIT Press, 1993, p. 229-255. 
Pub, 2008.

Thinking linguistically: a scientific approach to language. Michigan: Blackwell

HORA, D.; CHRISTIANO, E. (Org.). Estudos Linguísticos: realidade brasileira. João Pessoa: Ideia, 1999.

ILARI, R. Locuções Negativas Polares: Reflexões sobre um tema de todo mundo. In: . Lingüística: questões e controvérsias. Uberaba: Fac. Integrada de Uberaba, 1984, p. 83-97. Série Estudos 10.

. A lingüística e o ensino da língua portuguesa. São Paulo: Martins Fontes, 1997.

. Linguagem - atividade constitutiva. (Ideias e Leituras de um aprendiz). Revista Letras, Curitiba, n. 61, 2003.

KATO, M. A. A gramática do letrado: questões para a teoria gramatical. In: MARQUES, M. A. et al. (Org.). Ciências da linguagem: trinta anos de investigação e ensino. Braga: CEHUM, 2005. p. 131-145.

KANTHACK, G. S. Sintaxe da língua portuguesa. EaD. v. 2. Ilhéus: UESC, 2011.

KENEDY, Eduardo. Curso básico de Linguística Gerativa. São Paulo: Contexto: 2013.

LUFT, C. P. Moderna gramática brasileira. Porto Alegre: Globo, 1986.

MARTINS, M. A.; COELHO, I.; CAVALCANTE, S. Variação sintática e gerativismo. In: MARTINS, M. A.; ABRAÇADO, J. A. (Org.). Mapeamento sociolinguístico do português brasileiro. São Paulo: Contexto, 2015. p. 221-247.

MATTOS E SILVA, R. V. O português são dois: novas fronteiras, velhos problemas. São Paulo: Parábola Editorial, 2004.

MIOTO, C. Negação sentencial no português brasileiro e o critério-Wh. Tese (Doutorado em Linguística) - Universidade de Campinas, Campinas, 1992.

Insular, 1991.

.; FIGUEIREDO SILVA, M. C.; LOPES, R. E. Manual de sintaxe. Florianópolis:

NEGRI, L. Zona de fronteira: a delimitação entre a semântica e a pragmática sob a lente das expressões de polaridade negativa. 2006. Tese (Doutorado em Linguística) Universidade Federal do Paraná, Curitiba, 151 p., 2006.

PERINI, M. A. Gramática descritiva do português. 2. ed. São Paulo: Ática, 1996.

. Estudos de Gramática Descritiva: as valências verbais. São Paulo: Parábola, 2008.

PIRES DE OLIVEIRA, R. Formalismos na linguística: uma reflexão crítica. In: BENTES, A. C., MUSSALIM. F. (Org.). Introdução à linguística: fundamentos epistemológicos. 2. ed., v. 3. São Paulo: Cortez Editora, 2004, p. 219-250.

PIRES DE OLIVEIRA, R.; QUAREZEMIN, S. Gramáticas na escola. Petrópolis: Vozes, 2016. 
SCHER, A. P.; MEDEIROS, A. B.; MINUSSI, R. D. Estrutura argumental em morfologia distribuída. In: NAVES, R. R. et al. (Org.). Estudos formais da gramática das línguas naturais. Goiânia: Cânone Editorial, 2009. p. 123-138.

SOUZA, L. M.; GRITTI, L. L.; PIRES DE OLIVEIRA, R. Um estudo sobre os itens de polaridade negativa no PB e seu licenciamento. Working Papers em Linguística, v. 9, n. 2, p. 23-40, 2008.

TARALLO, F. Por uma sociolinguística românica paramétrica. Ensaios de Linguística, n. 13 , p. 51-84, 1987.

; KATO, M. A. Harmonia trans-sistêmica: variação inter e intralingüística. Preedição, n. 5, p. 315-353, 1989.

VICENTE, H.; PILATI, E. Teoria gerativa e "ensino" de gramática: uma releitura dos parâmetros curriculares nacionais. Verbum - cadernos de pós-graduação, n. 2, p. 4-14, 2012.

WESTPHAL, G. Aspectos do conhecimento lingüístico. Seminário Lingüística e ensino da Língua Portuguesa. Anais do Seminário de Linguística e Ensino da Língua Portuguesa. Porto Alegre: Edipucrs, 1994.

Data de submissão: 02/08/2017

Data de aceite: 10/10/2017 